\title{
Anti-KIR Monoclonal Antibody IPH 2101
}

National Cancer Institute

\section{Source}

National Cancer Institute. Anti-KIR Monoclonal Antibody IPH 2101. NCI Thesaurus. Code C78464.

A human monoclonal antibody directed against the human inhibitory killer IgG-like receptor (KIR) with potential immunostimulating and antineoplastic activities. Anti-KIR monoclonal antibody IPH 2101 binds to the KIR receptor expressed on human natural killer (NK) cells, which may prevent KIR-mediated inhibition of NK cells and permit NK cellmediated anti-tumor cytotoxicity. KIRs are surface glycoproteins that bind to major histocompatibility complex (MHC)/human leukocyte antigen (HLA) class I subtypes on target cells; binding of KIRs inhibits NK cell-mediated cytotoxicity. 